\title{
The selection of an optimal transportation strategy in urgent stroke missions: a simulation study
}

\author{
Jukka Pappinen ${ }^{1,2^{*}} \mathbb{D}$, Tuuli Miettinen ${ }^{3,4}$, Päivi Laukkanen-Nevala ${ }^{1}$, Pekka Jäkälä ${ }^{3,4}$, Anne-Mari Kantanen ${ }^{4}$,
} Pekka Mäntyselkä5,6 and Jouni Kurola ${ }^{7}$

\begin{abstract}
Background: Stroke causes death, disability and increases the use of healthcare resources worldwide. The outcome of intravenous thrombolysis and mechanical endovascular thrombectomy highly depends on the delay from symptom onset to initiation of definitive treatment. The purpose of this study was to compare the various patient transportation strategies to minimize pre-hospital delays.

Methods: Emergency medical services (EMS) mission locations and ambulance response times in Finland with urgent stroke-suspected dispatch codes were collected from Emergency Response Centre (ERC) records between 1 January 2016 and 31 December 2016. Four transport scenarios were simulated for each mission, comparing ground and helicopter transportation to hospital with different treatment capabilities.

Results: In 2016, a total of 20,513 urgent stroke-suspected missions occurred in Finland. Of these, we were able to locate and calculate a route to scenario-based hospitals in $98.7 \%(20,240)$ of the missions.

For ground transport, the estimated median pre-hospital time to a thrombolysis-capable and thrombectomycapable hospital were 54.5 min (95\% confidence interval (Cl), 31.7-111.4) and 94.4 min (95\% Cl, 33.3-195.8), respectively. Should patients be transported on the ground to thrombectomy-capable hospitals only, the prehospital time would increase in 11,003 (54.4\%) of missions, most of which were in rural areas.

With the fastest possible transportation method, the estimated mean transport time to a thrombectomy-capable hospital was $80.84 \mathrm{~min}$ (median, $80.80 \mathrm{~min} ; 95 \% \mathrm{Cl}, 33.3-143.1$ ). Helicopter transportation was the fastest method in $68.8 \%(13,921)$ of missions, and the time saved was greater than 30 min in $27.1 \%$ (5475) of missions. In rural areas, helicopter transportation was the fastest option in nearly all missions if dispatched simultaneously with ground ambulance.
\end{abstract}

Conclusion: Helicopter transportation may significantly decrease pre-hospital delays for stroke patients, especially in rural areas, but the selection of an optimal transportation method or chain of methods should be determined caseby-case.

Keywords: Emergency medical services, Geographic information systems, HEMS, Stroke, Simulation

\footnotetext{
* Correspondence: jukka.pappinen@finnhems.fi

${ }^{1}$ FinnHEMS Research and Development Unit, Lentäjäntie 3, Fl-01530 Vantaa,

Finland

${ }^{2}$ University of Eastern Finland, Faculty of Health Sciences, P.O. Box 1627,

Fl-70211 Kuopio, Finland

Full list of author information is available at the end of the article
}

(c) The Author(s). 2020 Open Access This article is licensed under a Creative Commons Attribution 4.0 International License, which permits use, sharing, adaptation, distribution and reproduction in any medium or format, as long as you give appropriate credit to the original author(s) and the source, provide a link to the Creative Commons licence, and indicate if changes were made. The images or other third party material in this article are included in the article's Creative Commons. licence, unless indicated otherwise in a credit line to the material. If material is not included in the article's Creative Commons licence and your intended use is not permitted by statutory regulation or exceeds the permitted use, you will need to obtain permission directly from the copyright holder. To view a copy of this licence, visit http://creativecommons.org/licenses/by/4.0/ The Creative Commons Public Domain Dedication waiver (http://creativecommons.org/publicdomain/zero/1.0/) applies to the data made available in this article, unless otherwise stated in a credit line to the data. 


\section{Introduction}

Acute ischemic stroke is the second most common cause of death worldwide [1] and results in disability for most patients and strain for healthcare services. In 2014, there were 20,467 new stroke events in Finland, which resulted in 201,892 patient days in a hospital ward. In 2007, the total costs of stroke patient care in Finland was approximately $\$ 1.6$ billion, which was approximately $7 \%$ of total health care expenditure [2].

Intravenous thrombolysis with tissue plasminogen activator (tPA) within $4.5 \mathrm{~h}$ after symptom onset is standard care for acute ischemic stroke. Recently, several randomized control trials also demonstrated the efficacy and safety of intra-arterial mechanical treatment [3-7]. In 2018, two studies were published that showed that thrombectomy for acute ischemic stroke was effective for up to 16 and $24 \mathrm{~h}$ among selected patients [8, 9]. Although studies have shown the efficacy, safety, and effectiveness of thrombectomy even after relatively long durations since symptom onset, the probability of good outcome is directly related to delay from symptom onset to reperfusion [10-12]. Thus, shortening the duration of the total process should be the main goal when developing acute stroke care system.

In most countries with organized acute healthcare services, equity in access to healthcare services is valued [13]. Several studies have focused on measuring, analysing, and shortening emergency medical services (EMS) response times [14-17]. Similarly, the current legislation in Finland demands that hospital districts determine, follow, and report EMS response times. In Finland, patients' travel times from home to hospital were previously evaluated [18], but the total time from an emergency call to the hospital (i.e., the pre-hospital time) has not been systematically evaluated, despite its relevance to the outcome of treatment.

Helicopter emergency medical services (HEMS) has been shown to effectively shorten pre-hospital times in certain patient groups [19], although the benefit highly depends on the general structure of EMS and the hospitals' location. The HEMS base location has been suggested as one mechanism to diminish inequity in access to emergency care, especially for trauma patients [20, 21].

This study aimed to 1) compare strategies for stroke patient transportation to determine an optimal strategy to minimize pre-hospital time and 2) report predicted interregional and urban-rural variations in delays in access to thrombolysis- or thrombectomy-capable hospitals. The study focuses on operational and logistics issues; thus, no economical evaluation is performed.

\section{Methods}

The Finnish Emergency Response Centre (ERC) is a state agency that is responsible for handling calls made to the public emergency number, 112. The ERC handles requests for EMS, police, fire and rescue, and emergency social services. Currently, there are six national ERCs to where 112 calls are routed based on the callers' geographic locations.

In EMS-related calls, dispatchers use a computer-aided and criteria-based risk assessment system to classify missions to one of four urgency classes (i.e., A-D) and 83 symptom and findings-based or injury mechanism-based classes. Dispatchers do not attempt to identify the patient, nor do they have access to electronic patient records. Legally, the caller or victim is not a patient until he or she is reached by an EMS unit. Every call is registered in ERC records.

EMS mission data between 1 January 2016 and 31 December 2016 with urgent suspected-stroke dispatch codes were collected from ERC records. In this study, we analysed only the mission and urgency class code, mission location, and response time of the first ambulance unit. The patients were not identified, nor were patients' hospital or EMS records accessed. The incident location and ground ambulance response time data were combined with the estimated transportation time to determine the time delay from an emergency call to patient arrival to the nearest hospital with stroke thrombolysis or thrombectomy capabilities. In Finland, only university hospitals $(n=5)$ have thrombectomy capability. Currently, the suspected-stoke criteria-based risk assessment tool used in ERCs is not designed or able to identify potential thrombolysis or thrombectomy candidates, and therefore, missions are mostly over-triaged [22].

We estimated the pre-hospital time for four scenarios for each mission:

- Direct ground ambulance transportation to the nearest hospital with computed tomography (CT) and thrombolysis capability (regional, central, or university hospital)

- Direct ground ambulance transportation to the nearest hospital with thrombectomy capability (university hospital)

- Helicopter transportation to the nearest university hospital with simultaneous ground EMS dispatch

- Helicopter transportation to the nearest university hospital with HEMS dispatched by EMS after primary evaluation

The catchment area for each hospital was determined by calculating a convex hull around a set of mission locations with the fastest road access to the same hospital. In this study, catchment areas did not align with administrative areas.

The area type for a mission scene was determined for each mission using the existing area classification method. Missions were divided into four groups by their 
area type: core urban, other urban, dispersed settlement, and other rural [23].

The open source GraphHopper [24] routing tool and OpenStreetMap [25] data were used to determine normal driving times, which were decreased by $20 \%$ to simulate a drive with the lights and siren based on literature [26]. Flight times were calculated via the great circle route and a flight speed of $220 \mathrm{~km} / \mathrm{h}$. Based on FinnHEMS and EMS statistics, we used 6 min as the dispatch to en-route time for a helicopter and $26 \mathrm{~min}$ as the on-scene time for both ambulances and helicopters. The patient unload time target at the hospital was $10 \mathrm{~min}$; however, it is known that this time varies among hospitals depending on the helipad location, and accurate data is not available.

The results were reported as median times with a 95\% confidence interval (CI). To support operative decision making with thrombectomy candidates, the effect of the estimated ground transportation time on the optimal transportation method was also reported.

\section{Results}

In 2016, ERCs dispatched 20,513 urgent stroke missions. We were able to locate and calculate the routes to the hospitals in 20,240 (98.7\%) missions, which were included in the study.

With ground transportation only, the estimated median pre-hospital time to thrombolysis-capable and thrombectomy-capable hospitals was $54.5 \mathrm{~min}$ (95\% CI, 31.7-111.4) and 94.4 $\mathrm{min}$ (95\% CI, 33.3-195.8), respectively.

If the patients were transported only to thrombectomy-capable hospitals, the pre-hospital time would increase in 11,003 (54.4\%) missions. The median increase was $66.8 \mathrm{~min}$ (95\% CI, 8.5-144.0). In rural areas, the pre-hospital time would increase in roughly $70 \%$ of the missions (Table 1).

Helicopter transportation to a thrombectomy-capable hospital was faster in $68.8 \%(13,921)$ of the missions, with a median time benefit of 23.7 min $(95 \%$ CI, 2.377.1), if HEMS was dispatched simultaneously with ground EMS (Table 2a). If HEMS was dispatched by paramedics after patient evaluation, the time benefit decreased. However, helicopter transportation to a thrombectomy-capable hospital would have been faster than ground transportation in 41.9\% (8483) of missions, with a median time benefit of $16.9 \mathrm{~min}$ (Table 2b). In rural areas, helicopter transportation would be the fastest option in nearly all missions if dispatched simultaneously with a ground ambulance.

With the fastest possible transportation method (i.e., ground EMS or HEMS), the estimated mean time to a thrombectomy-capable hospital was 80.84 min (median, 80.80; 95\% CI, 33.3-143.1). HEMS transportation was the fastest method in $68.8 \%(13,921)$ of missions, and the time saved was greater than $30 \mathrm{~min}$ in $27.1 \%$ (5475) of missions (Table 2a).

Helicopter transportation is increasingly becoming the optimal choice when ground transportation time increases. Should the ground ambulance crew dispatch HEMS after primary evaluation, helicopter transportation was estimated to be the fastest option in most cases with greater than $80 \mathrm{~min}$ ground transportation time (Fig. 1). If HEMS is dispatched simultaneously with a ground ambulance, helicopter transportation is the fastest choice in cases where estimated ground transport time exceeds $40 \mathrm{~min}$ (Fig. 2).

A supplementary thematic map shows a nationwide distribution of stroke-suspected missions and the fastest transportation methods (Supplementary file 1).

\section{Discussion}

The main finding of this study indicates that utilization of helicopter transportation in time-critical conditions could diminish the total pre-hospital time, improve access to emergency care, and increase the equality between rural and urban areas. In stroke patients, access to thrombectomy could be significantly improved via helicopter transportation.

Currently, ERC dispatchers over-triage strokesuspected missions, which results inefficient EMS resource use. Most patients with urgent stroke-suspected codes are not thrombolysis or thrombectomy candidates [22]. However, it is not possible to identify potential

Table 1 The total pre-hospital time using ground transportation only in the simulation

\begin{tabular}{|c|c|c|c|c|c|}
\hline & & \multicolumn{2}{|c|}{ Total pre-hospital time with ground transportation (min) } & \multicolumn{2}{|c|}{$\begin{array}{l}\text { Additional delay if transported directly to a } \\
\text { thrombectomy-capable hospital }\end{array}$} \\
\hline & & Thrombolysis-capable hospital & Thrombectomy-capable hospital & & \\
\hline & $n$ & median $(95 \% \mathrm{Cl})$ & median $(95 \% \mathrm{Cl})$ & $N(\%)$ & median $(95 \% \mathrm{Cl})$ \\
\hline Core urban & 4796 & $32.6(29.3-80.5)$ & $78.4(30.5-177.7)$ & $2410(50.3)$ & $76.1(16.4-144.6)$ \\
\hline Other urban & 12,305 & $54.8(34.4-106.0)$ & $89.8(36.8-193.6)$ & $6434(52.3)$ & $65.9(7.6-144.0)$ \\
\hline Dispersed settlement & 2852 & $84.3(51.9-134.7)$ & $127.0(64.3-219.6)$ & $1948(68.3)$ & $63.8(5.8-144.0)$ \\
\hline Other rural & 287 & $96.3(54.1-166.9)$ & $148.3(69.7-257.6)$ & $211(73.5)$ & $65.1(7.7-144.0)$ \\
\hline Total & 20,240 & $54.5(31.7-111.4)$ & 94.4 (33.3-195.8) & $11,003(54.4)$ & $66.8(8.5-144.0)$ \\
\hline
\end{tabular}


Table 2 The pre-hospital time saved by helicopter transportation compared to ground transportation

\begin{tabular}{|c|c|c|c|}
\hline \multirow[t]{2}{*}{ a) } & \multicolumn{2}{|c|}{ Simultaneous dispatch } & \multirow[b]{2}{*}{$>30$ min saved $(\%)$} \\
\hline & N (\%) & Median $(95 \% \mathrm{Cl})$ & \\
\hline Core urban & $2551(53.2)$ & $19.1(1.8-58.4)$ & $635(13.2)$ \\
\hline Other urban & $8303(67.5)$ & $21.6(1.9-64.5)$ & $3037(24.7)$ \\
\hline Dispersed settlement & $2784(97.6)$ & $34.2(6.4-92.4)$ & $1590(55.8)$ \\
\hline Other rural & $283(98.6)$ & $47.9(10.8-141.7)$ & $213(74.2)$ \\
\hline Total & $13,921(68.8)$ & $23.7(2.3-77.1)$ & $5475(27.1)$ \\
\hline \multirow[t]{2}{*}{ b) } & \multicolumn{2}{|c|}{ dispatch after primary evaluation } & \\
\hline & N (\%) & median $(95 \% \mathrm{Cl})$ & $>30$ min saved $(\%)$ \\
\hline Core urban & $1546(32.2)$ & $13.3(1.1-75.3)$ & $283(5.9)$ \\
\hline Other urban & $4819(39.2)$ & $17.7(1.9-76.3)$ & $1286(10.5)$ \\
\hline Dispersed settlement & $1885(66.1)$ & $18.6(1.4-85.7)$ & $545(19.1)$ \\
\hline Other rural & $233(81.2)$ & $24.0(3.0-110.9)$ & 97 (33.8) \\
\hline Total & $8483(41.9)$ & $16.9(1.6-75.7)$ & $2211(10.9)$ \\
\hline
\end{tabular}

patients more accurately with the data available. To effectively use helicopter transportation, which is relatively expensive, ERC dispatchers' ability to recognize symptoms of stroke and preferably identify those with major artery occlusion that would thus benefit from thrombectomy needs to be improved. For example, real-time video calls via mobile phone might offer a usable tool to evaluate the condition of a stroke patient.

Another problem is the selection of the receiving hospital. Typically, the nearest hospital has at least thrombolysis capability, but thrombectomy-capable hospitals are often further away. The length of additional transportation delays that are acceptable to provide better treatment capabilities is unknown. Door-to-needle time variations among hospitals should be considered in models to improve specificity; however, such benchmarking data is not yet available.

The transportation of a patient to the nearest hospital for imaging and, if indicated, the initiation of intravenous thrombolysis treatment that continues during secondary transport to a thrombectomy-capable hospital (i.e., the drip and ship strategy) may offer faster

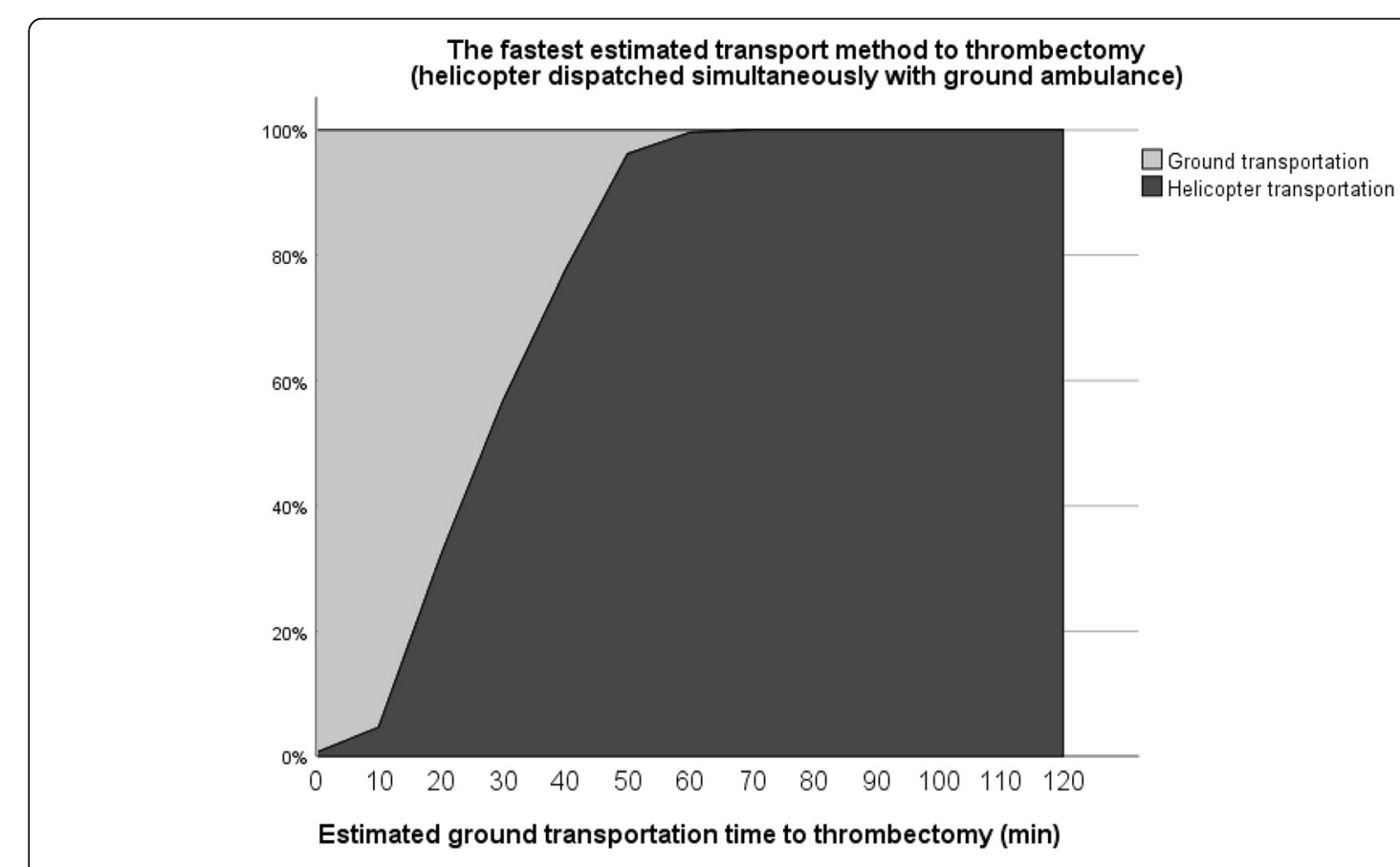

Fig. 1 The fastest estimated transportation method to thrombectomy when HEMS is dispatched by ground ambulance crew 


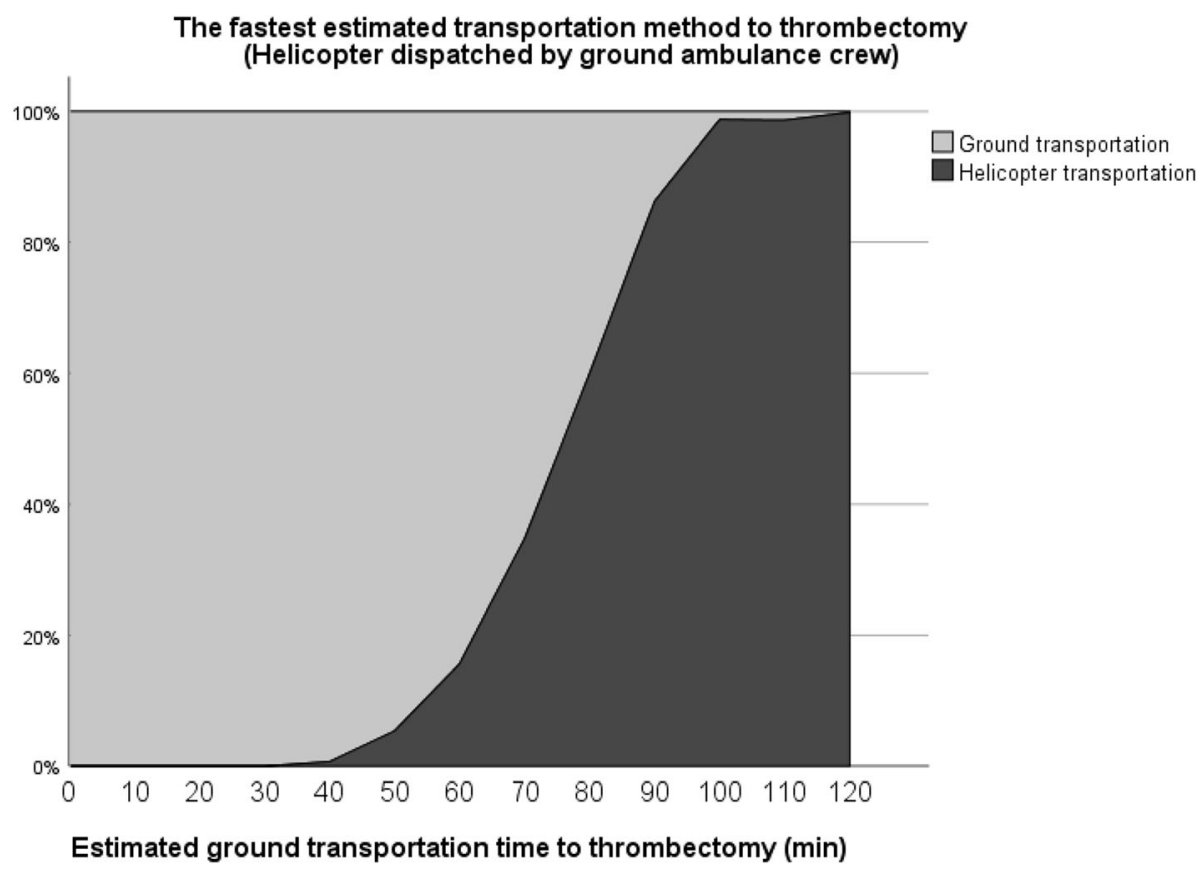

Fig. 2 The fastest estimated transportation method to thrombectomy with simultaneous HEMS and ground ambulance dispatch

diagnosis and treatment initiation for certain patient groups. However, the outcomes are dependent on outof-hospital and in-hospital processes and transportation delays.

The analysis suggests that the balance between optimal transportation methods is somewhat labile. The effect of relatively small changes in assumptions, driving times, or unit locations on mission onset may change the optimum transportation method and the optimum receiving hospital. The time to transport a patient from a hospital helipad to an emergency room (ER) may negate the time benefit from faster helicopter transportation. The options are often dichotomous and/or limiting and choices in one mission might alter the available choices in simultaneous missions or the next mission in the same area. Machine-learning systems might offer a reasonable method to estimate the outcomes of different options and support decision-making in real-time.

To use methods presented in this study to support decision-making in everyday practice, both pre-hospital and in-hospital delays in every phase of the logistic chain should be studied with comprehensive and accurate data collection. An economic evaluation should be performed to further evaluate costs and benefits of different transport strategies. Due to constantly changing unit locations, weather or road conditions, pre-calculated response time maps, and plans may lead to the selection of non-optimal transportation methods. A real-time decision support system utilizing current unit location, weather, and traffic data would be beneficial for decision-making during individual missions.

\section{Conclusions}

Helicopter transportation may significantly decrease stroke patients' pre-hospital time, especially in rural areas, but the selection of an optimal transportation method or chain of methods should be determined caseby-case.

\section{Supplementary information}

Supplementary information accompanies this paper at https://doi.org/10. 1186/s13049-020-00747-4.

Additional file 1. A thematic map showing the distribution of strokesuspected missions in 2016 in Finland with the fastest estimated transportation method indicated.

\section{Abbreviations}

HD: Hospital District; EMS: Emergency Medical Services; HEMS: Helicopter Emergency Medical Services; ERC: Emergency Response Centre;

ER: Emergency Room

\section{Acknowledgements}

We thank Jukka Tennilä and Jante Jomppanen from the FinnHEMS Research and Development Unit for their support in programming the routing software tool and processing the data.

Map data copyrighted OpenStreetMap contributors and available from https://www.openstreetmap.org

\section{Authors' contributions}

JP was a major contributor to the conception and writing of the manuscript and contributed to interpretation of the data. PLN provided valuable input to analysis and interpretation of the data and writing the manuscript. TM, PJ, A-MK, PM and JK made substantial contributions to the conception, design, 
analysis and interpretation of the data and writing the manuscript. All the authors have read and approved the final manuscript.

\section{Funding}

FinnHEMS Research and Development Unit resources have been used to collect and analyse the data.

\section{Availability of data and materials}

Anonymized data are available upon reasonable request from the correspondence author (https://orcid.org/0000-0002-1174-8669).

\section{Ethics approval and consent to participate}

The Medical Ethics Committee of the Northern Savo Hospital District approved this study on 25 April 2017 (141/2017).

\section{Consent for publication}

Not applicable.

\section{Competing interests}

JP and PL-N are employees of FinnHEMS and have received non-financial support from FinnHEMS during the conduct of the study. Other authors do not have relationships or activities that could appear to have influenced the submitted work

\section{Author details}

${ }^{1}$ FinnHEMS Research and Development Unit, Lentäjäntie 3, Fl-01530 Vantaa, Finland. ${ }^{2}$ University of Eastern Finland, Faculty of Health Sciences, P.O. Box 1627, Fl-70211 Kuopio, Finland. ${ }^{3}$ University of Eastern Finland, Institute of Clinical Medicine, Unit of Neurology, Kuopio, Finland. ${ }^{4}$ Neuro Center, Kuopio University Hospital, P.O.B. 100, FI-70029 KYS Kuopio, Finland. ${ }^{5}$ University of Eastern Finland, School of Medicine, P.O. Box 1627, Fl-70211 Kuopio, Finland. ${ }^{6}$ Primary Health Care Unit, Kuopio University Hospital, Kuopio, Finland.

${ }^{7}$ Centre for Pre-hospital Emergency Care, Kuopio University Hospital, P.O. Box 1777, Fl-70210 Kuopio, Finland.

Received: 29 April 2020 Accepted: 27 May 2020

Published online: 01 June 2020

\section{References}

1. Feigin VL, Norrving B, Mensah GA. Global burden of stroke. Circ Res. 2017; 120:439

2. Meretoja A, Kaste M, Roine RO, Juntunen M, Linna M, Hillbom M, et al. Direct costs of patients with stroke can be continuously monitored on a national level: performance, effectiveness, and costs of treatment episodes in stroke (PERFECT stroke) database in Finland. Stroke. 2011;42:2007-12.

3. Berkhemer OA, Fransen PSS, Beumer D, van den Berg LA, Lingsma HF, Yoo $\mathrm{AJ}$, et al. A randomized trial of Intraarterial treatment for acute ischemic stroke. New Engl J Medicine. 2015;372:11-20.

4. Goyal M, Demchuk AM, Menon BK, Eesa M, Rempel JL, Thornton J, et al. Randomized assessment of rapid endovascular treatment of ischemic stroke. New Engl J Medicine. 2015;372:1019-30.

5. Campbell BCV, Mitchell PJ, Kleinig TJ, Dewey HM, Churilov L, Yassi N, et al. Endovascular therapy for ischemic stroke with perfusion-imaging selection New Engl J Medicine. 2015;372:1009-18.

6. Jovin TG, Chamorro A, Cobo E, de Miquel MA, Molina CA, Rovira A, et al. Thrombectomy within 8 hours after symptom onset in ischemic stroke. New Engl J Medicine. 2015:372:2296-306.

7. Saver JL, Goyal M, Bonafe A, Diener H-C, Levy El, Pereira VM, et al. Stentretriever thrombectomy after intravenous t-PA vs. t-PA alone in stroke. New Engl J Medicine. 2015;372:2285-95.

8. Albers GW, Marks MP, Kemp S, Christensen S, Tsai JP, Ortega-Gutierrez S, et al. Thrombectomy for stroke at 6 to 16 hours with selection by perfusion imaging. New Engl J Medicine. 2018:378:708-18.

9. Sheinberg DL, McCarthy DJ, Peterson EC, Starke RM. DEFUSE-3 trial: reinforcing evidence for extended endovascular intervention time window for ischemic stroke. World Neurosurg. 2018;112:275-6.

10. Fransen PSS, Berkhemer OA, Lingsma HF, Beumer D, van den Berg LA, Yoo $A J$, et al. Time to reperfusion and treatment effect for acute ischemic stroke: a randomized clinical trial. Jama Neurol. 2015;73:1-7.
11. Saver JL, Goyal M, van der Lugt A, Menon BK, Majoie CBLM, Dippel DW, et al. Time to treatment with endovascular Thrombectomy and outcomes from ischemic stroke: a meta-analysis. Jama. 2016;316:1279-88.

12. Emberson J, Lees KR, Lyden P, Blackwell L, Albers G, Bluhmki E, et al. Effect of treatment delay, age, and stroke severity on the effects of intravenous thrombolysis with alteplase for acute ischaemic stroke: a meta-analysis of individual patient data from randomised trials. Lancet. 2014;384:1929-35.

13. Oliver A, Mossialos E. Equity of access to health care: outlining the foundations for action. J Epidemiol Commun H. 2004:58:655.

14. Dibene JC, Maldonado Y, Vera C, de Oliveira M, Trujillo L, Schütze O. Optimizing the location of ambulances in Tijuana. Mexico Comput Biol Med. 2017:80:107-13.

15. Leknes H, Aartun ES, Andersson H, Christiansen M, Granberg TA. Strategic ambulance location for heterogeneous regions. Eur J Oper Res. 2017;260: 122-33.

16. Nickel S, Reuter-Oppermann M, Saldanha-da-Gama F. Ambulance location under stochastic demand: a sampling approach. Operations Res Heal Care. 2016;8:24-32.

17. Zaffar MA, Rajagopalan HK, Saydam C, Mayorga M, Sharer E. Coverage, survivability or response time: a comparative study of performance statistics used in ambulance location models via simulation-optimization. Operations Res Heal Care. 2016:11:1-12.

18. Huotari $T$, Antikainen $H$, Keistinen $T$, Rusanen J. Accessibility of tertiary hospitals in Finland: a comparison of administrative and normative catchment areas. Soc Sci Med. 2017;182:60-7.

19. Mommsen $\mathrm{P}$, Bradt $\mathrm{N}$, Zeckey $\mathrm{C}$, Andruszkow $\mathrm{H}$, Petri M, Frink M, et al. Comparison of helicopter and ground emergency medical service: a retrospective analysis of a German rescue helicopter base. Technol Health Care. 2012;20:49-56

20. Branas CC, MacKenzie EJ, Williams JC, Schwab CW, Teter HM, Flanigan MC, et al. Access to trauma centers in the United States. Jama. 2005;293:2626-33.

21. Hameed SM, Schuurman N, Razek T, Boone D, Heest RV, Taulu T, et al, Access to trauma Systems in Canada. J Trauma Inj Infect Critical Care. 2010; 69:1350-61

22. Hoikka M, Länkimäki S, Silfvast T, Ala-Kokko TI. Medical priority dispatch codes-comparison with National Early Warning Score. Scand J Trauma Resusc Emerg Med. 2016;24:142. https://doi.org/10.1186/s13049-016-0336-y.

23. Pappinen J, Laukkanen-Nevala P, Mantyselka P, Kurola J. Development and implementation of a geographical area categorisation method with targeted performance indicators for nationwide EMS in Finland. Scand J Trauma Resusc Emerg Med. 2018;26:41.

24. Karich P, Schroder S. GraphHopper directions API with route optimization. 2017. https:// https://graphhopper.com.

25. OpenStreetMap 2018. http://openstreetmap.org. Accessed 2 May 2019.

26. Murray B, Kue R. The use of emergency lights and sirens by ambulances and their effect on patient outcomes and public safety: a comprehensive review of the literature. Prehosp Disaster Med. 2017;32:209-16.

\section{Publisher's Note}

Springer Nature remains neutral with regard to jurisdictional claims in published maps and institutional affiliations.

Ready to submit your research? Choose BMC and benefit from:

- fast, convenient online submission

- thorough peer review by experienced researchers in your field

- rapid publication on acceptance

- support for research data, including large and complex data types

- gold Open Access which fosters wider collaboration and increased citations

- maximum visibility for your research: over $100 \mathrm{M}$ website views per year

At BMC, research is always in progress.

Learn more biomedcentral.com/submissions 